\title{
Does idiopathic Parkinsonism in Aberdeen follow intrauterine influenza?
}

\author{
KLAUS P EBMEIER, * WILliAM J MUTCH, $\dagger$ SHEILA A CALDER,* \\ JOHN R CRAWFORD, * LESLEY STEWART, * JOHN O A BESSON*
}

From the Department of Mental Health, University of Aberdeen, ${ }^{*}$ and the Department of Medicine, Ninewells Hospital and Medical School, Dundee, $\uparrow U K$

SUMMARY A study is presented which fails to replicate a recent report that peak years of birth of patients later developing Parkinson's disease are related to the influenza pandemics of the period 1890-1930. The years of birth of a whole population cohort of 243 patients suffering from Parkinson's disease examined in Aberdeen in 1983 and reexamined in 1986/7 were compared with deaths due to influenza in the City of Aberdeen in the years 1900-1930. Although a significant peak of Parkinson births (compared with the age profile of the Aberdeen population in 1983) occurred in 1902, there appeared to be no systematic relationship between Parkinson births and influenza deaths. In addition, no season of birth effect could be detected in a comparison with 232 matched controls. The presence of peaks of birth years, for whatever aetiological reason, is of significance to epidemiological studies in that prevalence estimates may be influenced by the year of study relative to these minicohorts.

Poskanzer and Schwab ${ }^{1}$ postulated that Parkinson's disease resulted, after a latent period, from infection with the influenza A virus. They suggested that the prevalence of the disease was following a cohort pattern related to exposure to the virus during the great pandemics, and that the prevalence would fall dramatically by the 1980 s. More recently, Mattock $e t$ $a l^{2}$ have presented data from two groups of patients with idiopathic Parkinsonism compared with matched controls. The authors found that peak years of birth of patients later developing Parkinson's disease were related to the influenza pandemics of the period 1890 1930. The present study is an attempt to replicate these results with the Aberdeen whole population sample ${ }^{34}$ of clinically examined patients and their age, sex and general practitioner matched controls.

Address for reprint requests: Dr K P Ebmeier, Lecturer in Mental Health, Department of Mental Health, University of Aberdeen, Medical Buildings, Foresterhil, Aberdeen AB9 2ZD.

Received 27 January 1989.

Accepted 6 February 1989

\section{Subjects and methods}

Data were available from 267 patients in the Aberdeen Community Survey. ${ }^{3}$ At follow-up, on average 3 years and 7 months later (range: 2 years 11 months to 3 years 10 months), two patients were found not to have Parkinson's disease, three patients were suffering from postencephalitic Parkinsonism, and 19 could not be traced or had moved away. They were, therefore, excluded from this analysis, which was based on 243 patients.

In 1983, 233 controls had been matched to patients by sex, age and general practice. At review one of these had developed Parkinson's disease and was withdrawn from this analysis. Estimates of the size of age-groups in the city of Aberdeen for mid-1983, from the Registrar-General's reports, were used as population at risk. Figures for mortality due to influenza in Aberdeen were also extracted from the Registrar-General's reports for Scotland. ${ }^{5}$ In order to produce comparable figures, raw numbers of patients born in any particular year (hereafter called births) were related to the population at risk, that is, persons born in the same year and surviving in Aberdeen to 1983. The boundaries of the city of Aberdeen were extended to their present limits in 1975 during the Scottish local government reorganisation, so that the population estimates for 1983 relate to the new city of Aberdeen. The original prevalence study, ${ }^{3}$ however, only examined patients from the old city limits, so that the 
population estimates used do not exactly reflect the population at risk. The overall population in Aberdeen in 1983 was 214,100 , while the figures for the old city limits, used for the original study, were from the 1981 census and amounted to 151,616. Unfortunately, a yearly breakdown of the age distribution was not readily available for the old city of Aberdeen, so that overall 1983 figures were used. Examining the age distribution in the two populations in available fiveyear bands showed similar proportions, so that the use of the 1983 figures appears justified. Chi-square tests were used to identify significant peaks. For this purpose, $2 \times 2$ tables were constructed using the number of patients born in a certain year, the number of all Aberdonians born in this year and surviving to 1983, and the number of patients and all Aberdonians born in the other 4 years of the quinquennium (that is, 1900-1904, 1905-1909 etc) containing the year in question. Power analysis ${ }^{6}$ suggests that for an excess of $100 \%$ to be detected in any birth year of Parkinson patients, approximately 4000 subjects will be required per test. This analysis assumes a significance level of 0.05 and a power of 0.8 (that is, the likelihood of a chi-square test to detect a significant result, given the ratio of cases to overall population). Season of birth effects were examined comparing patients and originally matched controls, using chi-square test. Power analysis suggests here that the number of available patients and controls (475) would allow for a quarterly excess of at least $30 \%$ to be detected in $70 \%$ of chisquare tests, assuming, again, a significance level of 0.05 .

\section{Results}

The numbers of patients and population at risk by year of birth, as well as influenza deaths in Aberdeen is shown in the table. The only significant peak of patient births occurred in 1902 (chi-square $=8 \cdot 87, \mathrm{p} \leqslant 0 \cdot 01$ ). The number of subjects born during the four quarters (January-March, April-June etc) was for patients: 7248-65-58, and for controls: 58-55-59-60. There were, therefore, no significant season of birth effects (chisquare $=2.05, \mathrm{df}=3, \mathrm{p}>0.05$ ).

The figure shows the yearly number of patient births plotted alongside yearly influenza deaths in Aberdeen. Although the 1902 peak of births is preceded by the peak of deaths due to the turn-of-the-century influenza pandemic, later peaks in influenza mortality are not followed by an excess of patient births. There was no significant year by year correlation between numbers of patient births and deaths due to influenza, even if every birth year was compared with the preceding year's influenza mortality.

\section{Discussion}

Within our population only the 1902 peak of births was significant. This could be due to a number of reasons: the mean age of onset of the overall cohort was 65 years, with patients in the peak year possibly developing the illness even later. Thus, many people born after 1918 may not all have developed the illness
Table Yearly incidence of births of patients later developing idiopathic Parkinson's disease, deaths due to influenza, and population surviving in 1983 in the City of Aberdeen

\begin{tabular}{|c|c|c|c|}
\hline Year & $\begin{array}{l}\text { Patients with } \\
\text { idiopathic } \\
\text { Parkinson's } \\
\text { disease surviving } \\
\text { to mid-1983 } \\
\text { by year of birth }\end{array}$ & $\begin{array}{l}\text { Deaths due } \\
\text { to influenza } \\
\text { per year }\end{array}$ & $\begin{array}{l}\text { Total population } \\
\text { surviving in } 1983 \\
\text { by year of birth }\end{array}$ \\
\hline $\begin{array}{r}<1900 \\
1900 \\
1901 \\
1902 \\
1903 \\
1904\end{array}$ & $\begin{array}{r}32 \\
3 \\
4 \\
18 \\
14 \\
8\end{array}$ & $\begin{array}{l}79 \\
44 \\
45 \\
24 \\
14\end{array}$ & $\begin{array}{r}2841 \\
665 \\
843 \\
923 \\
1010 \\
1184\end{array}$ \\
\hline $\begin{array}{l}1905 \\
1906 \\
1907 \\
1908 \\
1909\end{array}$ & $\begin{array}{r}14 \\
7 \\
8 \\
13 \\
17\end{array}$ & $\begin{array}{r}33 \\
13 \\
9 \\
11 \\
12\end{array}$ & $\begin{array}{l}1293 \\
1376 \\
1427 \\
1583 \\
1612\end{array}$ \\
\hline $\begin{array}{l}1910 \\
1911 \\
1912 \\
1913 \\
1914\end{array}$ & $\begin{array}{r}12 \\
11 \\
8 \\
7 \\
8\end{array}$ & $\begin{array}{r}5 \\
6 \\
13 \\
8 \\
12\end{array}$ & $\begin{array}{l}1782 \\
1737 \\
1827 \\
1892 \\
1946\end{array}$ \\
\hline $\begin{array}{l}1915 \\
1916 \\
1917 \\
1918 \\
1919\end{array}$ & $\begin{array}{l}7 \\
9 \\
3 \\
1 \\
4\end{array}$ & $\begin{array}{l}11 \\
10 \\
10 \\
38 \\
31\end{array}$ & $\begin{array}{l}2015 \\
1905 \\
1784 \\
1580 \\
1641\end{array}$ \\
\hline $\begin{array}{l}1920 \\
1921 \\
1922 \\
1923 \\
1924\end{array}$ & $\begin{array}{l}5 \\
3 \\
2 \\
4 \\
2\end{array}$ & $\begin{array}{r}14 \\
28 \\
101 \\
11 \\
52\end{array}$ & $\begin{array}{l}2655 \\
2486 \\
2423 \\
2347 \\
2356\end{array}$ \\
\hline $\begin{array}{l}1925 \\
1926 \\
1927 \\
1928 \\
1929\end{array}$ & $\begin{array}{l}1 \\
1 \\
1 \\
2 \\
1\end{array}$ & $\begin{array}{l}18 \\
32 \\
41 \\
22 \\
71\end{array}$ & $\begin{array}{l}2356 \\
2445 \\
2450 \\
2451 \\
2488\end{array}$ \\
\hline $\begin{array}{l}1930 \\
1931-39\end{array}$ & $\begin{array}{r}1 \\
12\end{array}$ & $\begin{array}{r}10 \\
245\end{array}$ & $\begin{array}{r}2389 \\
21355\end{array}$ \\
\hline
\end{tabular}

by 1983. Consequently, later peaks apparent on inspection of the birth year profile (fig) might still become significant once all potential patients have actually developed the illness. In addition, the definition of quinquennia adopted from Mattock et als

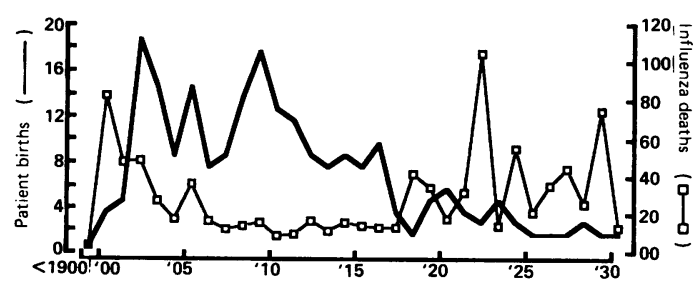

Fig Number of patients with idiopathic Parkinson's disease surviving to 1983 by birth year and influenza deaths per year in Aberdeen. 
paper ${ }^{2}$ might obscure actual peaks if, for example, the first and fifth year were peak years. However, post-hoc analysis comparing apparent peak years with the two preceding and the two following years did not produce any additional significant results. Finally, there is a small possibility that the adoption of a larger patient population might have resulted in more significant results. Figures of patient births and surviving population at risk are only comparable, if there was no increased risk of death for patients. This assumption is not true for the years before 1913, since we found an increased risk of death within $3 \frac{1}{2}$ years in the over 70 s suffering from Parkinson's disease in Aberdeen (Ebmeier $e t$ al, submitted for publication). This effect would obscure any early peaks of births, which makes the observed 1902 peak even more convincing. Examining seasonal excesses of birth has led to positive and replicable findings in certain neuro-psychiatric conditions.' With our relatively small numbers, we could not replicate, however, Mattock et $a / \mathrm{s}^{2}$ findings of a seasonal excess of births in Parkinson's disease.

Whilst the lack of an association between peaks of patient births and influenza deaths could be due to all of the aforementioned causes responsible for the absence of significant birth peaks it might be due to the varying degree of neurotropy of different virus strains, ${ }^{2}$ or even the failure of deaths to act as a reliable marker of the full extent of potential in utero infection by the influenza virus. For example, the 1918-1919 pandemic seems to have produced fewer deaths in Aberdeen than in the 1929 pandemic, but this may not mean that fewer people were affected by the virus. Also, patients may not have been conceived or carried in utero in Aberdeen, and thus the influenza mortality data may not be relevant to their risk of exposure to the virus. It is also possible that an analysis of quarterly rather than yearly figures might reveal a pattern of association which is obscured by the averaging process. A re-analysis of our data with special emphasis on short term fluctuations of numbers and a comparison with deaths due to a number of different viral infections is currently under way (Kerridge et al, in preparation).

Our failure to replicate Mattock et al's results might be related to sample differences or to geographical factors and the distance between catchment areas, which could have resulted in a different pattern of mortality due to influenza. It is clear, however, that the evidence for an association between the risk of prenatal influenza infection and the later development of
Parkinson's disease requires critical assessment. Finally, examination of patients' birth data in the fig shows a number of peaks for whatever aetiological reason, particularly for the years 1902, 1905 and 1909. The great majority of people likely to develop Parkinson's disease from these birth years are likely to have already done so, and thus in cross sectional prevalence studies these might almost appear as mini-cohorts. Such findings may be of importance to epidemiological studies because the prevalence may be influenced by the year of study relative to these minicohorts. It may for example explain why in an attempt to update Mutch's sample in 1987-88 using an identical procedure, less than 50 new patients have been found in Aberdeen, while 116 patients have died in the same period (unpublished observation). This observation may also explain some of the differences in crosssectional prevalence rates reported throughout the past 20-30 years and stresses the need for well-conducted longitudinal studies such as has been established in Aberdeen by Mutch et al.

The financial support of the Parkinson's Disease Society of the United Kingdom is gratefully acknowledged. The authors thank Mrs J Fleming, Grampian Health Board Information Unit, for the Aberdeen population estimates.

\section{References}

1 Poskanzer DC, Schwab RS. Cohort analysis of Parkinson's syndrome: evidence for a single aetiology related to subclinical infection about 1920.J Chron Dis 1963;16:961-73.

2 Mattock CH, Marmot M, Stern G. Could Parkinson's disease follow intra-uterine influenza?: A speculative hypothesis. $J$ Neurol Neurosurg Psychiatry 1988;51:753-6.

3 Mutch WJ, Dingwall-Fordyce I, Downie AE, Paterson JG, Roy SK. Parkinson's disease in a Scottish city. $\mathrm{Br}$ Med J 1986;292:534-6.

4 Mutch WJ, Strudwick A, Roy SK, Downie AW. Parkinson's disease: Disability, review and management. $\mathrm{Br}$ Med J 1986;293:675-7.

5 The Registrar General. Annual Reports of the Registrar General of Scotland 1900-1930; No. 46-76, Edinburgh: HMSO.

6 Kraemer HC, Thiemann S. How Many Subjects? Statistical Power Analysis in Research. Newbury Park, Cal.: Sage Publications, 1987.

7 Hare EH. Season of birth in schizophrenia and neurosis. Am J Psychiatry 1975;132:1168-71. 